\title{
ADAM SMITH E O USO OBJETIVO DA ECONOMIA COMO FORMA PARA A OBTENÇÃO DO DIREITO FUNDAMENTAL A LIBERDADE
}

\author{
ADAM SMITH AND THE OBJECTIVE USE OF ECONOMY AS A WAY \\ TO OBTAIN THE FUNDAMENTAL RIGHT TO LIBERTY
}

Luiz Edmundo Celso Borba

\section{Resumo}

A contribuição de Adam Smith para o liberalismo foi grandiosa, mas ela não se circunscreve a trazer uma busca ensandecida e desarrazoada por liberdade, como se todos os custos fossem possíveis para tal intento. Adam Smith traz o nascedouro para os direitos fundamentais, ao clamar pela necessidade de reconhecimento das liberdades individuais, embora antevisse problemas para o exercício sem limites de tais faculdades. A ideia do texto está em trazer a perspectiva inicial para a construção dos direitos fundamentais, em um prisma individual e após a sua ponderação em um espectro coletivo, assim como a discussão posterior de quais deverão prevalecer.

Palavras chave: Direitos Fundamentais. Adam Smith e Direitos Subjetivos x Direitos Objetivos.

\begin{abstract}
The contribution of Adam Smith for liberalism was great, but it is not limited to bringing an insane and unreasonable quest for freedom, as if all the costs were possible for such purpose. Adam Smith brings the birthplace of fundamental rights, to call for the need of individual liberties recognition, although predicting problems for the exercise of such powers without limits. The idea of the text is to bring the initial outlook for the construction of fundamental rights in an individual prism and after its weighting in a mass spectrum as well as the subsequent discussion which should prevail.
\end{abstract}

Keywords: Fundamental Rights. Adam Smith, and Subjective Rights x Objectives Rights. 


\section{ASPECTOS INTRODUTÓRIOS: DIREITOS SUBJETIVOS X DIREITOS OBJETIVOS}

Este trabalho busca trazer alguns aspectos do embate travado por Adam Smith, David Hume e outros empiristas, contra séculos de história do pensamento filosófico dominados pelo platonismo, e os efeitos deste ontologismo preponderante na academia ocidental, avessos ao empirismo. Trar-se-ão os problemas e discussões que construíram o cenário histórico e ideológico no período da primeira edição de A Riqueza das Nações, para melhor entenderemos o motivo para se clamar a liberalidade de uma forma tão visceral, motivo que inclina a avaliação:

0 mundo de Adam Smith originou-se da expansão colonial das monarquias autocráticas do século XVI, que logo levou ao entrechoque de suas fronteiras e interesses. A esta altura, pode-se indicar como origem do parlamentarismo europeu a crescente resistência da burguesia em ascensão contra as taxas sempre maiores para a manutenção desses impérios, o privilégio comprado contra o hereditário, o parlamento como um amortecedor entre o interesse geral e o individual. Na América do Norte, onde as colônias não obtiveram representação no parlamento inglês, a situação culminou no que Smith chama de "atuais distúrbios": "Riqueza das Nações" teve sua última edição exatamente em 1776. Na França, uma situação mais grave culminaria na Revolução Francesa [...]l (RODRIGUES, 2011, p. 20)

A importância da obra filosófico-econômica de Adam Smith é, usualmente, definida pelos efeitos de sua influência como o marco inicial para o enfoque científico dos fenômenos: produção, consumo e distribuição de bens e serviços; assim como suas interações, tornando de extremo interesse a discussão desses ares metodológicos e políticos trazidos em: “A Riqueza das Nações”, ao Smith apresentar seus principais aspectos teóricos e normativos, de modo a fornecer, para o leitor, uma visão agregada do conjunto de suas proposições analíticas, das quais a obra deriva a construção da Economia Política Clássica, como ramo científico. Como isso pode nos ajudar no vislumbre do empirismo hodierno?

Também se faz preciso ressaltar o que se estabelece neste introito: “Direitos Subjetivos x Direitos Objetivos". Procuraremos entender se há como reconhecer qualquer direito social, difuso ou coletivo, do que se extrai da 
obra de Adam Smith e de outros autores que desenvolvem suas teorias, a exemplo dos pragmatistas jurídicos norte-americanos: Oliver Wendell Holmes Junior e Richard Posner, sem se reconhecer, antes, o indivíduo.

A luta de Adam Smith, destarte, não foi a de se proteger a unidade social (o indivíduo) a todo e qualquer custo, pois a defesa do sujeito viabiliza entender a necessidade sucedânea de defesa da coletividade, devendo estas proteções ocorrerem de forma concomitante, caso contrário o resultado seria catastrófico, por existir uma defesa extrema em favor dos produtores (liberalismo) ou em favor dos consumidores/trabalhadores (socialismo), dois modelos histórica e comprovadamente falhos.

A falha, frise-se, será alvo de pesquisa deste artigo, ao se avaliar se o excesso de liberdade ou a contraposição de sua quase ausência, estimulam ou inibem o "egoísmo", não sopesando o crescimento individual do cidadão, possível impulsor do crescimento social. Será o meio termo a via mais sensata, espelhando a visão neoliberal, quando a fonte geradora de riquezas não poderá ser negada, assim como o elo mais fraco, porém mais numeroso e essencial para o desenvolvimento da economia? Estas são as ponderações a serem tratadas em sucessivo.

\section{A “RIQUEZA DAS NAÇõES" E A TRANSFORMAÇÃO DO DIREITO: O SUJEITO GANHA VOZ FRENTE AO ASPECTO PURAMENTE OBJETIVO.}

Do ponto de vista formal, a teoria econômica apresentada em: A Riqueza das Nações é essencialmente uma teoria do/para o progresso econômico, cujo cerne é clara e concisamente apresentado em suas primeiras páginas: a riqueza ou o bem-estar das nações é identificado com seu produto anual per capita que é determinado pela produtividade do trabalho "útil" ou "produtivo", entendido como o que produz um excedente de valor sobre seu custo de reprodução; e pela relação entre o número de trabalhadores empregados, produtivamente engajados frente o volume total da população (SMITH, 2003, p. 18 a 27).

Embora Smith atribuísse, explicitamente, maior importância ao primeiro desses determinantes como fator causal, a dinâmica de seu modelo de crescimento pode ser melhor entendida como um processo 
de "causalidade circular cumulativa" e que, em seus traços essenciais, consiste no seguinte: o crescimento da produtividade do trabalho, originado em mudanças na divisão e especialização do processo de trabalho, ao proporcionar o aumento do excedente sobre os salários permite o crescimento do estoque de capital, variável determinante do volume de emprego produtivo; a pressão da demanda por mão-de-obra sobre o mercado de trabalho, causada pelo processo de acumulação de capital, provoca um crescimento concomitante dos salários e, pela melhora das condições de vida dos trabalhadores, da população; o aumento paralelo do emprego, salários e população amplia o tamanho dos mercados que, para um dado estoque de capital, é o determinante básico da extensão da divisão do trabalho, iniciando-se assim a espiral de crescimento, entre outras causas (SMITH, 2003, p. 427 e 428).

E são nas últimas páginas da Teoria dos Sentimentos Morais que Adam Smith anuncia a intenção de trazer as bases da sua filosofia moral para os princípios gerais a orientarem as leis e o governo, nos mais variados aspectos, mas de forma precisa, não tão teórica quanto as produzidas por seus predecessores, sem tantas regras de dever, mas com mecanismos para reconhecer e lidar com a realidade, em permanente e pragmática mutabilidade (SMITH, 2003, p. 427 e 428).

Adam Smith, destarte, almejava criar um sistema normativo com funcionalidade entre as nações, facilitando a ideia de um livre comércio, de uma nova realidade entre os mercados mundiais o que facilitaria o desenvolvimento de toda a raça humana (SMITH, 2003, p. 4181 e ss.); e isso provocou e provoca a ira e a indignação de muitos filósofos até os dias de hoje. ${ }^{1}$ Vejamos o início das críticas de Karl Marx a Adam Smith e a David Ricardo:

Indivíduos que produzem em sociedade, ou seja a produção de indivíduos socialmente determinada: eis naturalmente o ponto de partida. 0 caçador e o pescador individuais e isolados, com que começam Smith e Ricardo, fazem parte das ficções pobremente imaginadas do século XVIII; são robinsonadas que, pese embora aos historiadores da civilização, não exprimem de modo nenhum uma simples reação contra um refinamento excessivo e um regresso aquilo que muito erradamente se entende como vida natural. 0 "contrato social" de Rousseau, que estabelece conexões e laços entre sujeitos independentes por natureza, tampouco se baseia em tal naturalismo. Este naturalismo não é senão a aparência, e 
aparência puramente estética, das grandes e pequenas robinsonadas. Na realidade, trata-se antes de uma antecipação da "sociedade civil", que se preparava desde o século XVI e que no século XVIII marchava a passos de gigante para a maturidade. Nesta sociedade de livre concorrência, cada indivíduo aparece desligado dos laços naturais, etc., que, em épocas históricas anteriores, faziam dele parte integrante de um conglomerado humano determinado e circunscrito. Este indivíduo do século XVIII é produto, por um lado, da decomposição das formas de sociedade feudais, e por outro, das novas forças produtivas desenvolvidas a partir do século XVI. E, aos profetas do século XVIII, (sobre cujos ombros se apoiam (sic) ainda totalmente Smith e Ricardo), este indivíduo aparece como um ideal cuja existência situavam no passado; não o vêem (sic) como um resultado histórico, mas sim como ponto de partida da história. E que, segundo a concepção que tinham da natureza humana, o indivíduo não aparece como produto histórico, mas sim como um dado da natureza pois, assim, está de acordo com a sua concepção da natureza humana. Até hoje, esta mistificação tem sido própria de todas as épocas novas. Stuart, que se opôs em muitos aspectos ao século XVIII e que, dada a sua condição de aristocrata, se ateve mais ao terreno histórico, evitou esta puerilidade. (MARX, 2010, p. 01)

A batalha secular entre os empiristas e os metafísicos (idealizadores de realidades a partir de e para o próprio intelecto), é travada mais uma vez, pois é clara a tentativa, de Karl Marx, ao atacar os escritos de Adam Smith e outros, de se atrelar a convivência social a um mundo fictício, onde todas as diferenças são dissipadas por um bem estar coletivo, por uma vida comum, sem egoísmo ou diferença de classes permitida pelo Estado e praticada integralmente por ele, sem nenhum privilégio.

Não há como se viabilizar tal postulado, na prática, pois é uma visão adversa a imagem de uma evolução das espécies defendida por Charles Darwin (BAGNOLI, 2008, p. 49), onde os mais pujantes sobrevivem e crescem para formar e gerar indivíduos mais fortes e melhor adaptados às realidades cotidianas, ainda que isso pareça "sem compaixão", ou o mais adjacente do irracional, é o mais próximo da realidade existencial de todos os seres vivos!

Negar isto não implica em se defender a beleza e pureza dos ideais, mas em se ficar cego ao lume da realidade, impulsionada pelo crescimento econômico e assim aprimorada, apesar de todos os percalços e falhas do sistema. Contudo Adam Smith, defende uma necessária e mais civilizada, 
aprimorada, forma de construir a convivência social e elege o bem estar da maioria a partir do bem estar pessoal. Era um passo, aparentemente, "irresponsável" ou "ingênuo", no melhor dos aspectos, mas seria o mais viável ao crescimento social, à sua época, diante de todo o cenário do absolutismo, que o circundava.

A viabilidade de toda a quebra do absolutismo, repita-se, dependia do desenvolvimento econômico, da mobilidade social, do estímulo à concorrência e, neste ínterim, as proposições de Marx fariam sentido (1983, p. 278), pois já seria o momento de repensar o liberalismo, de trazer, mais uma vez, o "afastado" Estado para o controle da ordem econômica, contudo de uma maneira mais reguladora, ao invés de uma postura mais direta sobre o mercado, ou seja, como produtor de bens e serviços (FIGUEIREDO, 2010).

Mas não da forma radical proposta por Marx, pois ela terminaria por retroceder a um modelo equiparável ao absolutista, quando poucas pessoas são dotadas de poderes, representatividade para determinar os interesses da maioria (pois não há, nem nunca houve, um socialismo efetivamente democrático, pelo que se experimentou pragmaticamente na história mundial), além de se instrumentar um sistema avesso ao crescimento pessoal, ao esforço particular, ao exercício da liberdade, pois até esta pertencerá ao Estado.

Por razões óbvias e diante da história do último século (URSS, Cuba, Coréia do Norte, China antes de reconhecer a propriedade privada, ainda que de uma forma restritiva, entre outras nações a adotarem o socialismo ou comunismo), tal modelo estava e está fadado ao fracasso, por não estimular/incentivar a produção lucrativa, basta analisar o crescimento tecnológico, populacional e científico da humanidade após o liberalismo, frente a realidade antes dele.

Hoje as assertivas de Adam Smith estão mais atuais do que nunca, ao analisarmos o pleno reconhecimento da função social da atividade empresarial, pelos empregos (diretos e indiretos), pelos tributos (diretos e indiretos) e pela movimentação do mercado propiciada, essa, ao contrário do que muito se afirma, não é uma concepção socialista (GRAU, 2010).

Embora a complementaridade faça a diferença, quando a liberdade defendida pelos liberais encontra a necessidade de uma adequação aos 
anseios sociais, fazendo surgir uma função social da propriedade como característica dos estados neoliberais, os primeiros a construírem um ponto equidistante entre esses dois extremos.

A função social da propriedade deve ser considerada em duas acepções principais: a primeira diz respeito ao fato do seu uso ser instrumento para a promoção de empregos (diretos e indiretos), tributos (diretos e indiretos) e a movimentação do mercado (entre produtores e consumidores, minorando o problema da escassez, do melhor emprego dos recursos naturais); e a segunda se relaciona com a ideia de que essa propriedade não possa ser usada de forma contrária aos resultados esperados na acepção anterior, possibilitando que o egoísmo de um grupo prejudique aos demais, diante do mau uso dos recursos econômicos. Destarte essas duas visões ou acepções do termo não se confundem, nem se excluem, pelo contrário, complementam-se.

Assim, Marx terminou indiretamente, ainda que ingenuamente (cabendo-lhe o mesmo adjetivo que dera a Smith, muito mais adequadamente), após outros desenvolverem e criticarem seus textos, orientando modificações ao modelo liberal, gerando o neoliberalismo, a necessidade de uma liberdade coesa com uma função social no aspecto de redução das desigualdades, uma preservação de interesses difusos e coletivos, como o meio ambiente, a cultura, os recursos naturais, viabilizando um crescimento nunca antes imaginado, nas mais variadas vertentes, ao, também, se proteger os polos hipossuficientes da relação humanas (consumidores e trabalhadores) corrigindo as maiores lacunas do modelo liberal.

Mas, retomando às lições de "A Riqueza das Nações", Adam Smith elabora uma divisão do períodos históricos de desenvolvimento do sistema produtivo, através do uso da terra nos seguintes estágios evolutivos (tendo cada um deles características sociopolíticas próprias): caça; pecuária; agricultura e as manufaturas, tratadas nos livros III a V.

Na fase da caça a estrutura do Estado não precisaria ser grandiosa, ou sequer seria necessário, pois cada homem usava sua iniciativa para promover sua própria subsistência e dos seus dependentes diretos, os conflitos interpessoais seriam raros, tornando desnecessária a própria ideia de bens privados, de demarcação de terras. 
Já no período da agricultura os seres humanos passam a se sedimentar em determinados espaços geográficos, tornando-se gregários, criando a necessidade de fomento e infraestrutura para a produção, momento em que se torna cogente um sistema de autoridade para um grupo de pessoas a acreditarem em propriedades privadas e na sua defesa perante terceiros.

Passa a existir um grau de autoridade e de subordinação para se manter esta estrutura, protegendo-a frente a outras nações, ou indivíduos procurando aumentar suas posses, pois até o período da Revolução Industrial, a propriedade de terras seria a principal representatividade de riquezas, até que a propriedade intelectual ganharia um importante relevo e repercussão (BARBOSA, 2009, p. 09 e ss.).

A produção da terra, por sua grandiosidade passa a carecer de trabalho de quem não seja seu proprietário, passando a existir servos, escravos, empregados aptos a laborarem na terra, no cultivo, por conseqüência; além de se demandarem exércitos e seguranças para proteção da terra e de outras eventuais formas de conflito observadas no cotidiano, ou até mesmo para a tomada de outras terras para o incremento do sistema produtivo.

Os conflitos sociais se dinamizam pela ausência de recursos para todas as pessoas, ${ }^{2}$ além da dificuldade para tornar, competitivamente, a terra produtiva, em uma escala mais evoluída, a da produção pecuária. As cidades surgem como uma decorrência da necessidade da administração de toda esta estrutura societária, com a formalização dos Estados, de sua composição de segurança, mediação de conflitos e possibilidade de uso da coerção e coação.

O período das manufaturas demonstra uma delegação excessiva de direitos e responsabilidades civis para o Estado, dotado de muitos poderes, demonstrando uma estrutura extremamente complexa que terminaria por desencadear o processo de industrialização e uma série de interesses difusos e coletivos surgiriam. A dificuldade seria a do Estado (seus gestores) entender e viabilizar a convivência de tantos interesses distintos e objetos de produção e consumo de bens e serviços.

Além do que o desenvolvimento das manufaturas, para Smith, ocasiona no crescimento dos centros urbanos, indiretamente provocando o 
próprio incremento das políticas de incentivo e crescimento agropecuário (SMITH, 2003, p. 511 e ss.).

Esta compreensão é importante para se aceitar a inviabilidade, tão proclamada no presente trabalho, do uso de um padrão axiológico, moral, aplicável à Antiguidade Clássica ser igualmente instrumental à época de Adam Smith, quanto mais nos dias de hoje, quando a própria Sociedade, por melhor ou pior que isso venha a ser, é muito mais atrelada aos custos da obediência ou desobediência do cumprimento das normas, do que ao dever de as cumprir por ser ético fazê-lo (HOLMES JUNIOR, 2006)! Vejamos a posição de Miguel Reale a tal respeito:

Há, pois, que distinguir um campo de Direito que, se não é imoral, é pelo menos amoral, o que induz a representar o Direito e a Moral como dois círculos secantes. Podemos dizer que dessas duas representações - de dois círculos concêntricos e dois círculos secantes, - a primeira corresponde à concepção ideal, e a segunda, à concepção real, ou pragmática, das relações entre Direito e a Moral. (2005, p. 43)

Isto posto, o Estado, tutor da ordem jurídica, será ambientado, na presente pesquisa, como, também, incluso no ideário de Rousseau (s/d, p. 19 a 21), como fruto de um contrato social; um instrumento essencial para regular, fiscalizar e viabilizar a vida em Sociedade, prestando-se a habilitar o ser humano a conviver de maneira mais harmônica e coordenada; tendo como destino um ponto que seria inalcançável para um indivíduo, ou grupo isolado, desarmados de um poder próprio cujo ente estatal pode congregar, por ser dotado de competência legislativa originária e do consecutivo poder de polícia.

Deve-se analisar que este contexto de Estado Democrático de Direito não foi construído tão facilmente, pois abrolha de séculos de insurgência e das experiências travadas pela Sociedade e a Academia, na busca por um modelo mais adequado, embora em eterna mutação, após os Estados Liberais propostos por Adam Smith. E, frisamos, tudo isso passa pela "ausência" temporária do Estado no controle das liberdades individuais, permitindo a queda do modelo absolutista.

E todas estas transformações são provenientes do experimentalismo aristotélico, ${ }^{3}$ resgatado por filósofos como Adam Smith, a ponto dele 
criar o conceito de uma "mão invisível do mercado", pois a livre iniciativa demandaria o afastamento estatal das ações econômicas e mais um vez as críticas surgiram, questionando e detonando esse excesso de liberdade para os hipersuficentes burgueses, despreocupados com o welfare state que sucedeu o liberalismo, como resposta a concentração de riquezas e a crescente desigualdade social.

Porém, diante de tudo o que foi construído no presente texto e no capítulo anterior, ao se demonstrar a importância da atividade empresarial e como o seu reconhecimento conseguiu incentivar e provocar, e ainda o faz, o desenvolvimento científico, filosófico, tecnológico da raça humana, não se deve recriminar Adam Smith, mas o readequar a realidade de hoje.

E esta é uma das mais duras críticas contra a Riqueza das Nações, patrocinadas pelos que discordam dos postulados de Smith, formatando a doutrina de não ser possível a intervenção estatal na economia, ainda que seja para controlar os interesses de comerciantes inescrupulosos ou guiados por um padrão de conduta, inclusive, avesso ao tratado dos sentimentos morais, ou seja, despreocupados com o bem-estar da maioria, ao se autopromoverem.

É a tese do livre comércio, da ingerência estatal sobre assuntos de cunho privado, uma vez que há uma separação absoluta entre Direito Público e Direito Privado para os liberais (SHAVEL, 2004, p. 608 e 609), pois para Adam Smith o mercado, com o tempo, corrigiria suas imperfeições (2003, p. 308 e ss.), ou seja, a "mão invisível" do mercado brindaria com seu toque, algo melhor do que a interferência do Estado poderia provocar (SHAVEL, 2004, p. 646; e MERCURO e MEDEMA, 2006, p. 99 e 100). Quem tem direito que lute por ele (IHERING, 2009)!

A luxúria, porém, poderia colocar em cheque a funcionalidade da tese de liberdade para o comércio de Smith, justificando-se na sua própria teoria dos sentimentos morais, pois o acúmulo de riquezas e a consecutiva sonegação ao bem-estar social fará parte do cotidiano dos produtores, embora esse seja o curso natural da evolução humana, tanto que, ciclicamente, repete-se.

Há de se assinalar o esforço de Adam Smith para impedir que a má versação de sua obra termine por criar uma espécie de classificação do ser humano (SMITH, 2003, p. 340 e ss), tanto que no livro V da Riqueza 
das Nações ele propõe uma série de limites para o exercício estatal de interferência sobre as relações privadas, mas ao mesmo tempo indica a necessidade do Poder Público defender os direitos humanos do trabalhador, além de propiciar meios de aperfeiçoamento e aprendizado com o intuito de reformular a estrutura social.

Para visualizar estas necessárias transformações sociais, cobrava-se a reformulação dos centros acadêmicos existentes à época, incentivando, no aluno, um imprescindível apreço pelo conhecimento que passará a ser a maior e verdadeira fonte de riqueza, por ser o melhor mecanismo para a sua distribuição dependeria de sua criação e a concessão de liberdade de expressão, de abertura dos centros universitários, não mais circunspecto aos membros da nobreza ou do alto clero (SMITH, 2003, p. 340 e ss.).

A própria reformulação do liberalismo, uma necessidade posterior, viria da acessibilidade ao conhecimento, com a abertura dos centros acadêmicos, tornando mais fácil perceber que a humanidade adentraria na era da economia, usando-a como um grande instrumento para o desenvolvimento, ou uma arma nefasta para a opressão social, caso a moral eleita por Smith fosse esquecida.

Logo Marx e outros opositores do liberalismo proposto por Adam Smith e David Hume, entre outros iluministas, só puderam exercer sua crítica, diante da própria existência deste modelo, como meio de colocar termo a uma estrutura secular absolutista e inaugurar uma nova academia, apta a construir uma nova Sociedade com maior poder de expressão e acima de tudo compromisso com a educação (SMITH, 2003,p. 962 e ss.).

A prova disto está no forte apelo ético que demarcou seus trabalhos, estabelecendo como o desenvolvimento e adequação do homem aos padrões morais, sempre mutáveis, crescendo com a experimentação e o desenvolvimento do estágio cognoscitivo da humanidade, como se capta em:

Os grandes fenômenos da natureza - as revoluções dos corpos celestes, os eclipses, os cometas, os trovões, relâmpagos e outros meteoros extraordinários; a geração, a vida, o crescimento e dissolução de plantas e animais - tudo isso são objetos que, por suscitarem necessariamente a admiração, naturalmente incitam a curiosidade dos homens a investigar suas causas. De início a superstição tentou saciar essa curiosidade, atribuindo todas essas aparições fantásticas à ação imediata dos deuses. Assim como esses grandes fenômenos são os primeiros objetos da curiosidade humana, também a 
ciência que pretende explicá-los deve necessariamente ter sido o primeiro ramo que se cultivou da filosofia. Daí que os primeiros filósofos, dos quais a história conservou alguns relatos, pareçam ser filósofos da natureza.

Em cada época e país do mundo, os homens necessariamente atentaram para o caráter, o desígnio e a ação uns dos outros, sendo então necessário estabelecer e aprovar, por consenso comum, inúmeras e respeitáveis regras e máximas de caráter. Tão logo surgiu a escrita, os sábios ou os que se imaginavam sábios naturalmente se empenharam em aumentar o número dessas máximas estabelecidas e respeitadas, e em exprimir o que eles mesmos entendiam por conduta apropriada ou inconveniente, ora na forma artificial de apólogos - tal como as chamadas fábulas de Esopo -, ora na forma mais simples dos apótemas ou ditos sábios - como os Provérbios de Salomão, os versos de Teógnis e Focílides, bem como algumas partes da obra de Hesíodo. Os homens poderiam continuar a se exprimir assim por muito tempo, unicamente para multiplicar o número daquelas máximas de prudência e moralidade, sem mesmo tentar arranjá-las numa ordem bastante distinta ou metódica, muito menos relacioná-las por um ou vários princípios gerais, dos quais todas elas seriam deduzidas, como os efeitos se deduzem das causas naturais. Foi nos rudes ensaios para um sistema de filosofia da natureza que se viu, pela primeira vez, nesses tempos antigos, a beleza de uma disposição sistemática das diferentes observações, associadas mediante uns poucos princípios. Algo semelhante se tentou fazer mais tarde com a moral. As máximas da vida comum foram dispostas numa certa ordem metódica, e relacionadas entre si por alguns princípios comuns, do mesmo modo como haviam ensaiado dispor e relacionar os fenômenos da natureza. A ciência pretende investigar e explicar esses princípios associativos é o que propriamente se chama de filosofia moral. (POSNER, 2010, p. 23)

E a visão de que a moral muda, em especial com o desenvolvimento dos setores de produção e consumo, uma parte significativa do comportamento e cotidiano humano, pode ser expressa, também, em Max Weber, ao dissecar a intersecção entre o Direito e a Economia:

É evidente que os dois modos de consideração se propõem problemas totalmente heterogêneos, que seus "objetos" não podem entrar imediatamente em contato, e que a "ordem jurídica" ideal da teoria do direito não tem diretamente nada a ver com o cosmo das ações econômicas efetivas, uma vez que ambos se encontram em planos diferentes: a primeira, no plano ideal de vigência pretendida; o segundo, nos acontecimentos reais. Quando, apesar disso, a ordem econômica e a jurídica estão numa relação bastante íntima, é porque esta última é entendida não em seu sentido jurídico mas no sociológico: como vigência empírica. 0 sentido da palavra 
"ordem jurídica" muda então completamente. Não significa um cosmos de normas interpretáveis como logicamente "corretas", mas um complexo de motivos efetivos que determinam as ações humanas reais cabe interpretar isso em detalhes. (2000, p. 210 e 211)

Nada a divergir da própria noção grega de economia, embora bem mais rudimentar e relacionada a o uso da "casa", mas sem esquecer a visão de comportamento, valores morais e o próprio Direito, como lembrado nas lições de Fábio Nusdeo:

Por enquanto basta guardar este conceito básico: a economia existe porque os recursos são sempre escassos frente a multiplicidade das necessidades humanas. Daí fazer sentido a origem etimológica da palavra, proveniente da expressão grega oikos+nomos, onde oikos ou oikia, no sentido mais amplo quer dizer casa e nomos norma ou normatização e, daí, dar ordem, organizar, administrar, prover. São palavras não sinônimas, evidentemente, mas cujos sentidos convergem para levar a idéia de que $a$ casa, vale dizer, a unidade onde se abriga a família, não se sustenta ou não a sustenta por si só, mas precisa passar por uma organização ou estar arrumada, organizada para tanto. E a conotação reforça-se ao considerar ter a casa na antiguidade um sentido mais abrangente do que o atual. Em primeiro lugar, porque a família de então era de âmbito mais amplo, incorporando não apenas pais e filhos, mas parentes outros como tios, primos, avós, além de número às vezes avantajado de agregados de diversa ordem, inclusive dependentes e escravos. Mais anda, a casa ou a família, assim ampliada, constituía uma unidade não limitada ao consumo, mas igualmente à produção, dentro do regime chamado de autoconsumo, onde eram em número relativamente reduzido os bens trazidos de fora.

(...omissis...)

Por outro lado, a etimologia: oikos+nomos põe em realce um dado essencial da realidade econômica, nem sempre devidamente lembrado ou trabalhado. É o da íntima relação entre Direito e Economia. Mais do que íntima relação, trata-se, na verdade, de uma profunda imbricação, pois os fatos econômicos são os que são e se apresentam de uma dada maneira em função direta de como se dá a organização ou normatização - nomos - a presidir a atividade desenvolvida na oikos ou num dado espaço físico ao qual ela possa se assimilar. E o nomos nada mais vem a ser do que as normas ou regras, estas objeto da ciência do Direito. (2010, p. 19) (grifos nossos)

É no início do livro III da Riqueza das Nações que Smith passa a falar como a riqueza terá um progresso natural no seio social, como apresentado 
páginas atrás, com o desenvolvimento das escalas de produção e consumo, através do aumento das trocas de produtos e serviços, por intermédio de dinheiro, inclusive entre o campo e as cidades, no tocante aos seus objetos de troca, muito embora defenda a supremacia da produção do campo. (SMITH, 2003, p. 473 e ss.)

Mas vale observar que, ainda naquele período, o uso da terra era mais relevante do que os outros sistemas de produção, algo modificado com a implementação da revolução industrial e o surgimento subsequente da propriedade imaterial, intelectual, como paradigma mais significativo para a economia (SMITH, 2003, p. 427 e 428), diante do crescente aporte de recursos empregados após a revolução industrial (BAGNOLI, 2008, p. 40).

A ideia de Smith seria a de uma separação necessária do Direito e a atividade econômica, através da livre concorrência, marcando um dos primeiros discursos a envolver moral, direito e economia, excluindo o Estado da tutela das atividades de produção e consumo, certo de que a moral considerada e edificada de forma subjetiva em uma Sociedade instruída para reclamar seus direitos, seria a melhor forma de relação entre Poder Público e população, propiciando o desenvolvimento das teses a serem tratadas nos capítulos posteriores.

O livre comércio é uma decorrência lógica da livre associação de pessoas para a produção de riquezas, fazendo com que todas as classes sociais se associassem, como achassem conveniente, na melhor defesa de seus interesses particulares (SMITH, 2003, p. 973 e ss.), construindo respostas mais coesas e "justas" em relação as dadas pelo Poder Estatal, até então caracterizado pelos abusos no exercício de poder (SMITH, 2003, p. 907), mais preocupado em servir aos interesses do governante; e o texto abaixo exemplifica sua posição sobre os altos custos para se manter este judiciário, e seus riscos, pois nem sempre ele é independente e faz valer a posição jurídica, a ética ou a econômica, em termos sociais:

Em Homero, quando Agamenon oferece a Aquiles, como prova de amizade, a soberania de sete cidades gregas, a única vantagem que menciona como provável resultado disso é ser honrado pelo povo com presentes. Enquanto esses presentes, enquanto os emolumentos da justiça ou do que se pode chamar de honorários do tribunal, constituíam a única receita normal que o soberano extraía de sua soberania, era difícil esperar, nem sequer decente 
propor, que desistisse deles completamente. Podia-se propor, como aliás frequentemente acontecia, que se regulamentassem e se fixassem esses emolumentos. Todavia, depois de serem assim regulamentados e fixados, continuava a ser muito difícil, para não dizer impossível, impedir uma pessoa que era todo-poderosa de estendê-los para além das regulamentações. Por isso, enquanto justiça - resultado inevitável da natureza arbitrária e incerta desses presentes - quase nunca admitia qualquer remédio eficaz. Mas, quando, por causas várias - sobretudo em razão do contínuo aumento dos gastos com a defesa da nação contra a invasão de outras nações -, os bens fundiários do soberano vieram a se tornar completamente insuficientes para custear as despesas da soberania, e quando se fez necessário que o povo, para sua própria segurança, contribuísse para cobrir essas despesas com impostos de diferentes espécies, parece ter-se tornado muito comum estipular que nem o soberano, nem seus bailios ou substitutos (os juízes), aceitam, sob qualquer pretexto, algum tipo de presente pela administração da justiça. Ao que parece, supõe-se que fosse mais fácil abolir integralmente os presentes do que regulamentá-los e fixá-los efetivamente. Estabeleceu-se que os juízes passariam a receber salários fixos, os quais supostamente deveriam compensar a perda de parte do que eventualmente lhes caberia dos antigos emolumentos da justiça, assim como os tributos mais do que compensaram o soberano pela perda dos dele. Considerou-se então que a justiça passaria a ser administrada gratuitamente.

No entanto, em país nenhum a justiça foi de fato administrada gratuitamente. (SMITH, 2003, p. 909 e 910)

Diante dessa assertiva, reconhece-se a ideia do próprio provimento jurídico, em sua esfera jurisdicional, sem esquecer das demais, implica em uma lato custo para a Sociedade, sem mencionar que nem sempre o judiciário será dotado de condições para ofertar a melhor solução para o caso sob litígio, por não entender do mercado, pior ainda quando o Poder Judiciário age atrelado ao que determina o Poder Executivo, em nada contribuindo para a discussão do interesse popular (SMITH, 2003, p. 915 e 916).

Só deveria caber ao Poder Público, na concepção de Adam Smith, interferir enquanto produtor nos serviços que fossem extremamente onerosos, ou impossíveis de serem feitos por particulares, em razão de seu alto custo, manutenção, etc., e por esta questão de viabilidade, algo que a nossa Constituição Federal de 1988, assimilou em seus artigos 173 e 174 . 
E essa "demonização" do modelo liberal de Adam Smith, por si só não convence, pois no exemplo da prática brasileira, a defesa de um Estado Social, aparentemente trazido pela Constituição Federal de 1988, nem sempre se revela como a proteção devida e perfeita, uma vez que a ausência do controle estatal traz a preocupação de ser prudente e acertado se afirmar que nem sempre os direitos fundamentais poderão ser analisados ao pé da letra, gerando para o hermeneuta a missão de buscar caminhos não tão frios e objetivos, mas consubstanciados nos axiomas principiológicos que orientam o ordenamento jurídico pátrio (CARVALHO, 2002, p. 140 a 143), visando o melhor interesse tangível à Sociedade como um todo; mas essa proteção tem um custo muito alto, por ser dificílimo especificar os limites, tornando possível hospedar ausências ou exageros.

Neste diapasão a defesa de Adam Smith das normas morais soaria quase que com as mesmas notas da defesa pretendida, pela doutrina atual, que superestima os princípios. Como se eles enclausurassem nossos ideais de certo e errado da forma mais perfeita e adequada e viabilizassem respostas corretas aos intérpretes do texto legal.

Só pelo fato de existirem várias acepções da palavra direito, revela-se que vários sentidos podem ser atribuídos a ela: 1ํo) o aspecto normativo (o direito escrito em um ordenamento e a ciência que o estuda); $2^{\circ}$ ) o aspecto fático (o acontecimento social e/ou histórico); e $3^{\circ}$ ) o aspecto axiológico (o direito como valor de ética e de efetiva justiça), (NÓBREGA, 1962, p. 26).

A alusão aos "princípios gerais" concerne aos axiomas existentes na ciência jurídica e sua inseparável junção ao direito positivado; de forma a implicar na aceitação de uma suprapositividade, quando da interpretação e integração da norma. Interessante, também, é o fato de o princípio ter um conteúdo axiológico, mas não ser um valor, propriamente; embora estes possam se traduzir em princípios (SALDANHA, 1998, p. 200 e 2001).

A suprapositividade alardeada pelos defensores dos Direitos Fundamentais indica um pseudo status de superioridade perante as demais pautas de conduta, sendo, inclusive despicienda de sua garantia através de uma norma legislada. O princípio seria superior a tal "verdade", pois dá espírito aos comandos gerais que rege, e, inclusive, a outros 
princípios. Pseudo status, pois na prática isso não se confirma e tudo se circunscreve ao provimento jurisdicional, nem sempre concedido com fulcro na norma posta.

Mesmo estes princípios, quando não são normas positivadas, jamais seriam sonegados ou afastados pelo hermeneuta em seu valoroso e árduo papel de trazer as abstratas normas escritas, objetivas, ao universo da subjetividade, aplicando-a ao caso concreto, atestando a subsunção de uma dada conduta com o comando legal, ou hipótese de incidência. Destarte, os princípios funcionam como tendências às quais o intérprete deverá seguir, pois estes axiomas sustentam os ordenamentos jurídicos e a ciência, ou arte, segundo muitos que os estudam. ${ }^{4}$

E esses, sucintamente, seriam os caminhos principais para a riqueza e o crescimento das nações, reconhecer que o jogo produtivo deveria ser abandonado pelo Estado, preocupado em fornecer acesso à educação (em especial às universidades), ao passo que conferia liberdade para as pessoas investirem seus recursos, direcionando-os melhor do que o Poder Público. A famosa mão invisível do mercado, autoregulatória.

A história, porém, revelou o que o Smith antevia nas entrelinhas do seu trabalho: a falta de controle entre as classes e os agentes econômicos propiciaria o caos, sendo este um mal necessário para quebrar o regime absolutista.

Desta forma, o arcabouço ético, para a observação construtiva e aplicativa do Direito, será visto de forma bastante variada, de acordo com os autores pontuados neste capítulo e no capítulo anterior, com as contribuições de Adam Smith.

E esta linha de ação, retrógrada e tacanha, do absolutismo, persistiu por séculos até a Declaração Francesa de 1789 e na Independência Americana iniciar a queda do absolutismo, quando a cidadania seria expandida para se tornar o grande albergue dos direitos humanos fundamentais, entendidos como direitos, relativos a defesa da liberdade e da igualdade, suscetíveis de concretização na cidade e no Estado; vivificando os direitos vinculados ao homem.

A questão da cidadania envolve moral e direito, na perspectiva de Smith, ao se criar à certeza da extensão dos direitos de um indivíduo frente ao poder maior do Estado, e a ética com a qual o mesmo será tratado; a 
validade, ou não, de entender o direito com base, meramente, no status do seu portador, ao se proteger os direitos humanos.

Os direitos fundamentais, ou civis, ou humanos recepcionados pelo ordenamento jurídico, integram o conceito de cidadania desde o nascituro do liberalismo, ganhando status constitucional ao serem declarados nos grandes textos básicos das nações democráticas, criando-se uma cidadania constitucional, defendida por um Estado de Direito (DIMOULIS, 2005 e MARTINS, 2007).

A liberdade terá de ser acobertada por condições mínimas para a fazer valer; posto que seria inútil ter uma liberdade para contratar, ou ir, ou vir, ou se expressar, sem se ter uma educação mínima para manifestar ideias e vontades. E tal "certeza" é o que torna lícito e plausível assumir a obrigação social de pagar tributos, fazendo com que quem possa contribuir, ajude à sociedade a se desenvolver como um todo, melhorando o padrão, a qualidade de vida e o sentimento de dignidade de cada cidadão, sem exceção (SILVA, 2006, p. 113).

Isto posto, os direitos políticos estão em grande sintonia com os direitos fundamentais; deles não derivam diretamente, mas surgem com uma consolidação (TORRES, 2001, p. 271). Os direitos políticos têm decisiva importância, também, para a fixação dos deveres fundamentais.

É o ideal de que a todos é lícito e facilitado pelo Estado, crescer com seu labor, seu esforço e de acordo com a proporção de sua livre iniciativa. É o direito de ganhar, amparado pelo direito de trabalhar em um mercado onde se opera a livre iniciativa, mas com limites necessários, sem os quais os direitos de outros cidadãos seriam solapados; exemplificando com a hipótese do consumidor vilipendiado por uma ação comercial sem nenhum limite para torná-la ética e aceitável.

\section{LIBERDADE E IGUALDADE, UMA DIFÍCIL PONDERAÇÃO PRÁTICA.}

A tríade liberdade, fraternidade e igualdade defendida pelo liberalismo ao longo dos séculos, mostra-se, atualmente, como conceitos muito vastos, ao mesmo tempo em que vazios e carentes de explicações mais aprofundadas e detalhadas ao se construir a plausibilidade de choque 
entre direitos fundamentais individuais com direitos fundamentais coletivos, por exemplo.

Enunciar mais esta tríade significa a tornar mais aplicável, pois caso tais conceitos permanecessem tão vastos, por incrível que pareça seu propósito de defesa de direitos fundamentais seria deturpado, equivocado. Como? Um exemplo, clássico, seria o choque entre a plena liberdade de contratar, do empregador, com a hipossuficiente e desigual trabalhador (levando-se em conta outro aspecto da tríade, a igualdade).

Caso não houvesse ao longo dos anos uma lapidação de tais conceitos, os mesmos perderiam sua posição de conquistas, para um status de mudança de controle do poder, tornando-o opressivo para a grande maioria, ao passo que uma minoria seria favorecida por uma hermenêutica viciada e tacanha, fruto de uma legislação, axiologicamente, absurda.

A igualdade é um conceito a ser preservado e adstrito a uma cuidadosa e sensata escala de valores, sendo estes, primordialmente, os interesses difusos e coletivos, que funcionam como apaziguadores das relações intersubjetivas.

Duas correntes principais foram edificadas com base neste conjunto de idéias e valores: a) o igualitarismo de Rousseau, trazendo axiomas de justiça e equanimidade para a igualdade; b) a liberal-moderada, restringindo a isonomia a aspectos meramente formais e impositores de uma conduta mais contida e menos intervencionista do Estado.

$\mathrm{Na}$ verdade a melhor alternativa seria a busca por uma mescla das duas correntes em seus pontos altos, pois ambas apresentam vicissitudes e benesses explanadas logo adiante: o igualitarismo de Rousseau é brilhante e atual, apesar de passados mais de dois séculos de sua criação; porém, há, na ótica do presente trabalho, uma lacuna ao se tratar da "justiça"!

Justiça para quem e quando? Sempre, sem exceção, levando em conta os "menos" favorecidos? Quais os valores prevalecentes? A natureza, o meio ambiente são preteríveis à uma comunidade que precisa cortar árvores, ou caçar animais (mesmo os fora de risco de extinção) para subsistir? O homem será mais importante que o meio onde vive e assim haverá de reconhecer o Estado? Liberdade ou Sociedade? 
São inúmeras perguntas, entre diversas, que servem para suscitar análises sob uma teoria centenária, que não visualizava, à época, tais problemas decorrentes do dinamismo da intersubjetividade.

Parece prudente e acertado se afirmar que nem sempre os direitos fundamentais poderão ser analisados ao pé da letra, gerando para o hermeneuta a missão de buscar caminhos não tão frios e objetivos, mas consubstanciados em axiomas visando o melhor interesse tangível, sendo dificílimo de ser especificado em seus limites, não hospedando ausências ou exageros (CANOTILHO, 1997, p. 170 e ss.).

A segunda corrente peca ao afastar o Estado da sociedade, pois é um ideário fruto de uma casta, burguesa, autosuficiente, dominante à época da elaboração de tal teoria. Ressalte-se o interesse na distância do Estado no tocante às atividades mercantis e correlatas.

E esta atuação do Estado requisitará uma atenção especial da academia, como já preconizara Adam Smith e se apresentou neste e no outro capítulo, para se evitarem maiores deméritos para a grande massa de comandados, em sua maioria miseráveis, que suportam um fardo de condições humanas indignas e desiguais, frente uma elite abastada e quase sem controle.

Destarte, a falta de intervenção do Estado nas atividades sociais interessa aos defensores de tal teoria, não tão preocupados com interesses legítimos e imperativos, inclusive por força de texto constitucional, mas com valores espúrios e meramente pecuniários. Em suma, o capital "deverá" preponderar frente ao homem desvalido.

A união das duas teorias ocasionaria na perfeita solução, adequando-se a busca, justificada, delimitada e axiológica pela justiça (interesse da maioria); com o devido afastamento do Estado das questões que não lhe convenham, não sejam de sua alçada, ou não condigam com o interesse da coletividade, mas sim de grupos aproveitadores do sofrimento da maioria.

Efetivar tais princípios com base nesta maneira mais racional e atual, frente à realidade temporal, deverá ser o norte de todo e qualquer jurista preocupado com valores éticos, de dignidade e de justiça; sua obrigação moral e dever jurídico, vinculando liberdade, igualdade e fraternidade ao conceito de cidadania (CANARIS, 2006).

Cidadania oriunda da antiguidade clássica, significando, à época, o elo entre o homem e a cidade, aferindo, primeiro, direitos e impondo obrigações, 
de forma a direcioná-lo para uma conduta cívica e consciente da ética e da justiça. Muito embora poucos, no lapso temporal ora sob análise, pudessem ser "pacientes" de tal prestação estatal (BRANCO, 2007, p. 230 e 231).

Com o decorrer do tempo e a ênfase aos valores pecuniários em detrimento aos demais, afastou-se a cidadania de uma correta conceituação, redefinindo-a como privilégio para os enquadrados num status apropriado para serem seus titulares, aos demais nada, ou muito pouco!

E tal linha de ação, retrógrada e tacanha, persistiu por séculos até a Declaração Francesa de 1789, quando a cidadania seria expandida para se tornar albergue de direitos fundamentais do homem, entendidos como direitos, da liberdade e igualdade, suscetíveis de concretização na cidade e no Estado; levando os direitos vinculados ao homem a serem ainda mais vívidos e buscados (CANOTILHO, 1997, p. 270 e ss.).

Esta política mudou para a classe agora dominante, mas não para a maioria ainda hoje solapada pelo Estado, não no tocante ao ordenamento, mas sim frente ao executivo e a falta de implementação destas políticas (CANARIS, 2006, p. 29), por isto mesmo essa defesa tão arraigada que fazemos aos princípios, nada mais é senão uma defesa ao próprio Adam Smith.

Portanto, voltamos ao tema dos conflitos entre os princípios, pois estas antinomias muitas vezes existiram, quer por uma questão meramente interpretativa, que por um claro choque entre os dispositivos éticos, positivados ou não. Isso se dá em razão de uma escolha ou eleição doutrinária dos princípios como os principais veículos introdutores dos direitos fundamentais; e será de sumária importância determinar os limites imanentes entre cada um dos princípios, e qual deverá prevalecer sobre o outro (SARMENTO in: TORRES, 2001, p. 38).

Para resolver tais conflitos, deverão ser utilizados três critérios básicos desenvolvidos pela doutrina: cronológico, hierárquico e por especialidade. $01^{\text {o }}$ diz que o princípio posterior deve prevalecer em caso de conflito; o $2^{\circ}$ reza a prevalência do princípio contido em norma de estrutura superior; e por fim o 3ํa norma mais especial, preponderará sobre a mais abrangente (DIMOULIS e MARTINS, 2007).

Canotilho (1997, p. 173) explicita uma possível atuação argumentativa, permitindo, verbi gratia, que comandos não explícitos, possam ser capturados, através de uma boa hermenêutica, por operadores jurídicos 
que os utilizarão como meio de solução para litígios, instrumentando-se com o princípio da ponderação de bens, visando evitar, ou minimizar ao máximo, o sacrifício destes; neste momento também deverá ser considerado o princípio da razoabilidade.

E essa ponderação sobre bens, jamais poderá versar sobre nada relativo ao núcleo essencial, dos direitos fundamentais, visto que jamais, os mesmos poderão ser solapados sob qualquer égide. Este campo que deveria-ser intangível por qualquer legislador, ou operador jurídico, traduz "o limite dos limites". Mas tal restrição poderá ser feita através de duas formas: abstrata (teoria pura) e relativa (com supedâneo no caso concreto, obviamente tal teoria é mais flexível e, portanto, de mais fácil aplicação) (SARLET, 2007).

\section{CONSIDERAÇÕES FINAIS: A RUPTURA PROVOCADA POR ADAM SMITH É INSTRUMENTAL PARA O SURGIMENTO DOS DIREITOS FUNDAMENTAIS DE PRIMEIRA GERAÇÃO.}

No final deste texto, gera-se um forte endosso aos trabalhos de Adam Smith, frente as críticas destrutivas aos seus trabalhos, patrocinadas pela visão Marxista e de seus seguidores, porém o liberalismo não foi de todo um mal, nem muito menos o socialismo, assim pode ser classificado, o equilíbrio e a razoabilidade entre os dois deve ser o grande guia para uma construção crítica, dialética e pragmática.

A questão é que os dois sistemas são radicais em suas escolhas e terminam por defender uma quase ausência completa do Estado ou uma existência quase onipresente. Por um lado se defende a esfera de produção e por outro a de produção e consumo.

Entendo, portanto, que o trabalhador se confunde com o consumidor, na medida que as pessoas vendem sua força de trabalho, sua atividade intelectual, seus esforço físico objetivando resultados financeiros que viabilizem um determinado padrão de consumo.

Os direitos fundamentais defendidos por Adam Smith, especificamente a liberdade, nos mais variados aspectos ligados a economia, demarcariam o início de todo esse processo, onde reconhecer o indivíduo se constituía como a chave para após se reconhecer o coletivo, mas este 
seria um passo a ser desenvolvido por outros, embora as pistas para tal caminho estavam estrategicamente escondidas na Teoria dos Sentimentos Morais e na Riqueza das Nações, com o viés social da norma moral.

Adam Smith, com isso, nas entrelinhas do seu trabalho, fomenta bases para o liberalismo e após o arcabouço pragmático para se alcançar o controle posterior e cogente para o excesso de liberdade necessária para romper o sistema absolutista, até por que os financiadores de tal ruptura demandavam por um retorno aos seus investimentos.

É injusta, ao meu ver, a recriminação da obra de Adam Smith e a pecha de uma ingenuidade que ele não teve, pelo contrário a ingenuidade pode ser do leitor menos atento das obras de Adam Smith, assim como todas as discussões que hoje travamos dependiam de um aspecto ponderado por ele: liberdade.

Agora, não havemos como concordar que o modelo prático de Adam Smith, proposto na Riqueza das Nações, deva ser fidedignamente aplicado hoje, posto que o mesmo demanda atualizações, em virtude da própria modificação social, como o próprio Smith o fez com as teorias de Aristóteles, enquadrando-as para a sua realidade.

Não visualizo, portanto, ao adentrar no cerne deste artigo, uma resposta radical em favor dos direitos de primeira ou de segunda geração, mas a necessidade de uma coexistência, pois não há como se defender o todo sem o mínimo de reconhecimento de cada parte que o integra.

As liberdades precisam existir, contanto que estejam devidamente limitadas, para se evitarem os excessos e os supervenientes conflitos de interesse, a real função do Direito em uma Democracia, motivo pelo qual os modelos de gestão político-econômica mais de centro, ou seja, que visualizam a proteção dos dois polos econômicos devem prevalecer, atualmente, para a implementação de uma democracia, como se apresentam os modelos neoliberais.

Porém, uma ressalva há de ser feita a intervenção do Estado deve ser idealizada como uma decorrência clara do nível de desigualdade existente entre as pessoas, posto que quanto maiores forem as desigualdades entre as classes sociais, políticas e econômicas, maior deverá ser a interferência do Estado e quanto menores forem as altercações menor a necessidade de sua ingerência. 
Sendo assim, não há um modelo estanque ou definitivo para fixarmos a produção, a interpretação ou a aplicação dos Direitos Fundamentais, pois tudo decorre, como assinalado pelo próprio Smith, da realidade pragmática, do momento sócio-econômico vivido e é por isto mesmo que a discussão não deve ser posta como eminentemente teórica, nem os postulados objetivos da academia de um país, deva ser adotada cabalmente por outra academia, essencialmente quando falamos de Europa e América do Sul, pois as diferentes realidades levam a diferentes ponderações práticas.

Os modelos formulados são uma valiosa ferramenta, mas elas dependem de sua aplicabilidade na realidade histórica e social de cada país. E isto, leva-me, mais uma vez a ter mais certeza nas teorias de Adam Smith e nas contribuições dadas pelas críticas de Marx, gênese do neoliberalismo.

As regras para os Direitos Fundamentais precisam atender e beneficiar a todos os "jogadores" do tabuleiro do mercado e só assim esta partida valerá a pena ser disputada por todos e para todos.

\section{NOTAS}

1 A exemplo de: MARX, Karl. Uma contribuição crítica para a economia política. Disponível em: <<http://www.livrosgratis.com.br/arquivos_livros/ma000084.pdf>>, coletado em: 28/09/2010.

2 Com a ideia da escassez tão central para o estudo da economia, quanto a concepção de satisfação.

3 Como tratado com maior afinco em (BORBA, 2012).

4 Há uma forte e dominante corrente que atesta ser a ciência jurídica, não um ramo científico, mas sim uma arte, tendo como exemplo: RORTY, Richard: Pragmatismo, filosofia analítica e ciência. In: PAULO Roberto Margutti Pinto; Cristina Magro; Ernesto Perini Frizzera Santos; e Lívia Guimarães (Orgs.): Filosofia analítica, pragmatismo e ciência. Belo Horizonte: Editora UFMG, 1998. pp 20-23. Embora concorde com tal posicionamento, devo afirmar que, conforme fala o próprio Rorty, ela é improfícua, caracterizando-se como eminentemente metafísica, algo igualmente criticável.

\section{REFERÊNCIAS}

BAGNOLI, Vicente. Direito e poder econômico. São Paulo: Campus/jurídico, 2008.

BARBOSA, Cláudio R. Propriedade intelectual. Rio de Janeiro: Campus, 2009.

BORBA, Luiz Edmundo Celso. A "esquina” histórica dos caminhos retóricos de aristóteles e dos pragmáticos de peirce em torno da ética: uma evolução de paradigmas.. In: BRANDÃO, Cláudio; SALDANHA, Nelson; FREITAS, Ricardo. 
(Org.). História do direito e do pensamento jurídico em perspectiva. São Paulo: Atlas, 2012. p. 570-604.

BRANCO, Paulo Gustavo Gonet, et al. Curso de direito constitucional. São Paulo: Saraiva, 2007.

CANARIS, Claus-Wilhem. Direitos fundamentais e direito privado. Coimbra: Almedina, 2006.

CANOTILHO, José Joaquim Gomes. Direito constitucional e teoria da Constituição. Coimbra: Almedina, 1997.

CARVALHO, Paulo de Barros. Curso de direito tributário. São Paulo: Saraiva, 2002.

DEICHSEL, Simon. Against the pragmatic justification for realism in economic methodology. In: Erasmus Journal for Philosophy and Economics, Volume 4, Issue 1, Spring 2011, p. 23-41. Disponível em: <<http://ejpe.org/pdf/4-1-art-2. pdf>>. Acesso em: 16 set. 2010.

DIMOULIS, Dimitri. Positivismo jurídico. São Paulo: Método, 2005.

DIMOULIS, Dimitri; MARTINS, Leonardo. Teoria geral dos direitos fundamentais. São Paulo: RT, 2007.

FIGUEIREDO, Leonardo Vizeu. Lições de direito econômico. São Paulo: Forense, 2010.

GRAU, Eros. Direito constitucional econômico. São Paulo: Malheiros, 2010.

HOLMES JR., Oliver Wendell. The Path of the Law. Texto disponível em: <<www. soriano-ph.com>>. Acesso em: 24 set. 2006.

HOOK, Sidney (Org.). Law and Philosophy - A Symposium. Ney York: Library of Congress, 1970.

MARX, Karl. Uma contribuição crítica para a economia política. Disponível em: <<http://www.livrosgratis.com.br/arquivos_livros/ma000084.pdf>>. Acesso em: 28 set. 2010.

MELLO, Celso de Albuquerque. "O § 2o do art. 5o da Constituição Federal; In: TORRES, Ricardo Lobo (org.). Teoria dos direitos fundamentais. Rio de Janeiro: Renovar, 2001.

NÓBREGA, J. Flóscolo. Introdução ao direito. Rio de Janeiro: José Konfino Editor, 1962. 
NUSDEO, Fábio. Curso de economia: introdução ao direito econômico. São Paulo: Revista dos Tribunais, 2010.

POSNER, Richard. Direito, pragmatismo e democracia. Tradução de Teresa Dias Carneiro. Rio de Janeiro: Forense, 2010.

REALE, Miguel. Lições preliminares de direito. São Paulo: Saraiva, 2005. p. 43.

RODRIGUES, Márcia. A história do pensamento econômico. Rio de Janeiro: Editora Minuano, 2011.

ROUSSEAU, Jean-Jacques. 0 contrato social. Coleção Grandes Mestres do Pensamento. São Paulo: Formar, (s/ d.).

SALDANHA, Nelson. Filosofia do direito. Rio de Janeiro: Renovar. 1998.

TORRES, Ricardo Lobo. "A Cidadania Multidimensional na Era dos Direitos"; In: TORRES, Ricardo Lobo (Org.). Teoria dos direitos fundamentais, Rio de Janeiro: Renovar, 2001.

WEBER, Max. Economia e sociedade. Brasília: Universidade de Brasília, 2000. v.1.

Recebido em: 22-3-2017

Aprovado em: 8-5-2017

\section{Luiz Edmundo Celso Borba}

Doutor em Filosofia e Teoria Geral do Direito pela Universidade Federal de Pernambuco (UFPE), mestre em Direito Tributário pela UFPE. Professor Adjunto da Universidade de Pernambuco (UPE), nas disciplinas de Direito Administrativo, Financeiro e Tributário e da Graduação em Direito da Faculdade Boa Viagem (FBV). E-mail: ledborba@hotmail.com

Universidade de Pernambuco (UPE).

Avenida Agamenon Magalhães, S/N - Santo Amaro - Recife - PE - 50100-010 